\title{
\& Research Square

\section{The observed thermal anomaly as an earthquake Precursor: A case study from the 1993 Latur earthquake prone area in Western India}

Vijay P Dimri ( $\sim$ vpdimri@gmail.com )

CSIR-National Geophysical Research Institute

\section{Simanchal Padhy}

National Geophysical Research Institute CSIR https://orcid.org/0000-0002-4741-1953

\section{N C Mondal}

National Geophysical Research Institute CSIR

\section{G K Reddy}

National Geophysical Research Institute CSIR

G G. Ramacharyulu

National Geophysical Research Institute CSIR

V S Singh

National Geophysical Research Institute CSIR

\section{S Sonkamble}

National Geophysical Research Institute CSIR

\section{Shanker}

National Geophysical Research Institute CSIR

\section{Research Letter}

Keywords: 1993 Latur earthquake, Earthquake precursor, Helium, Tropospheric temperature, Ground water level

Posted Date: January 11th, 2021

DOI: https://doi.org/10.21203/rs.3.rs-67573/v2

License: (c) (i) This work is licensed under a Creative Commons Attribution 4.0 International License.

Read Full License 


\section{Abstract}

We report and discuss monitoring of short-term variations of widely used multi-geophysical parameters in Latur-Killari area in western India, the region that witnessed a major devastating earthquake in 1993. An abnormal rise in atmospheric temperature of more than $20^{\circ} \mathrm{C}$ at $11200 \mathrm{~m}$ height was observed in the airflight just $100 \mathrm{~km}$ away from Latur during a monsoon period. We investigated the cause of such abnormal rise in temperature in relation to the seismicity of the area for the 1993 Latur earthquake along with the continuous monitoring of ground water level and soil Helium gas for a week under a precursory 'quick please' operation in the study area. There were no seismic signals associated with this precursor rise that led to the suspension of the operation after a week time. It is also observed that this thermal anomaly is not followed by any major earthquake over the area, which has larger implications in atmosphere research area, suggesting a detailed investigation of such anomaly that may provide a better insight into the precursory behavior of the observed thermal anomaly by overcoming the constraints of accurate retrieval of temperature due to inadequate penetration of Satellite based thermal sensor into thick clouds. Findings of this study certainly call for continuous monitoring of temperature over the earthquake prone areas to gain insight into the physics of short-lived variation in temperature over spatially limited extent, especially over the earthquake prone areas for improved seismic hazard assessment.

\section{Introduction}

Peninsular India is regarded as one of the hotspots of generating past moderate to strong earthquakes that found enigmatic seismogenesis having no plausible earthquake precursors for the region devoid of collisional, subduction and active magmatism (Mukhopadhyay et al. 2006; Mishra et al. 2008). The LaturKillari area in western India, one of the stable continental regions (SCRs) of the world, witnessed a major devastating earthquake in 1993.

Earthquake precursors are difficult to recognize because of the complex processes occurring in the Earth's crust, various types of earthquake mechanisms, and the lack of extensive and continuous geophysical and geochemical monitoring in most earthquake prone areas including the SCRs of the world. A variety of earthquake precursors, including geophysical, geochemical (Barsukov et al. 1985; King 1986), geodetic, seismological (Sengupta et al. 2018), biophysical, thermal (Guangmeng 2008), and other phenomena have been identified preceding major earthquakes. Some of these precursors include: the sudden change in seismicity characterized by seismic $b$-value characterizing the magnitude-frequency distribution, and fractal dimension of spatio-temporal distribution of epicenetrs (Dimri 2005a, 2005b; Ravi Prakash and Dimri, 2000; Subhadra et al. 2018), fluctuation in ground-water levels due to change in stress (Yuce and Ugurluoglu 2003), change of gravity and magnetic field of earth and electrical resistivity of sub-surface rock materials, including selfpotential values (Hayakawa and Fujinawa 1994; Noritomi 1978; Hayakawa and Fujinawa 1994), release 
of Radon and Helium gas (Wakita et al. 1978), rise in skin surface and atmospheric temperature (Choudhury et al. 2006; Guangmeng 2008), atmospheric storm-related wind drag on continents, fault zone rock layer heating associated with the solar and geomagnetic storms, difference in electromagnetic emission (ULF/VLF). Several operational earthquake forecasting methodologies have been developed to validate earthquake precursors without any common consensus on different parameters discussed by different researchers (Dutta et al. 2012a-b; Outkin et al. 2013 a-b; Dutta et al. 2013).

Creation of micro-fractures due to the slow build-up of strain resulting in escape of radiogenic helium and radon provides the basis of geochemical methods of earthquake prediction (Barsukov et al. 1985; Virk et al. 2001). Geochemical and hydrological signals preceding the major earthquakes have been used for earthquake prediction, especially in China, Japan, the former Soviet Union, and the United States (King 1986). Yuce and Ugurluoglu (2003) have shown the ground water level changes in 19 exploration wells and recorded pre-seismic, co-seismic, and post-seismic water level changes during the Izmit and Duzce earthquakes in the Eskisehir region, Turkey. Comparing the precursory anomalies associated with the 1995 Kobe earthquake and the 1978 Izo-Oshima earthquake, Silver and Wakita (1996) concluded that many pre-seismic anomalies are true precursors, although the anomalies may exhibit some response heterogeneity. Wakita et al (1978) observed a high concentration of helium up to $350 \mathrm{ppm}$ in soil gas along a fault during the 1966 Matsushiro earthquake swarm in Japan. Radon variation in spring water before and after the 1999 Chamoli earthquake, Garhwal Himalaya, India was reported by Choubey et al. (1999) and they found that their observation was in conjecture with radon variability for other earthquakes occurred, elsewhere in the world (Outkin et al. 2013a-b).

Anomalous changes in various geo-electrical parameters were observed before several earthquakes in different parts of the world (Noritomi 1978; Hayakawa and Fujinawa 1994). Thus, anomalous changes in various precursory parameters have been documented in different parts of the world. However, there is no consensus on the statistical significance of these precursors and their reliability, due to the lack of reproducibility and understanding of the underlying physical mechanisms. For example, a successful prediction of an earthquake based on some of these precursory studies was carried out by China for the 1975 Haicheng, China earthquake (M 7.3), but another prediction in 1976 using the similar precursory studies was considered as a failure in Tangshan (Ludwin 2004). Similarly, as another example in India, it was observed that the temporal variations in dissolved helium cannot be ascribed to the contemporary enhanced seismic activity in Bhavnagar in Gujarat, India (Gupta and Deshpande 2003). In the same way, although there are several pieces of evidence for many thermal anomalies in National Centers for Environmental Prediction (NCEP) data, but not all cases of thermal anomaly correspond to the earthquake occurrence. So, it appears that different precursors may appear at different stages in different places of earthquake preparation zones. Then, the rule of game is 'leave nothing to chance' to probe further if one or two precursors appear. We, therefore, need to improve how to reduce such false alarm in earthquake precursor studies. To this end, we think multi-geophysical data, together with possibly temperature, pressure, humidity of the atmosphere and seismicity and so on may be used to correlate the sub-surface processes like occurrence of earthquakes with atmospheric phenomena. 
Anomalous variations on local to regional scale can occur in lithosphere, atmosphere, and ionosphere which can be explained by the Lithosphere-Atmosphere-lonosphere Coupling (LAIC) model that has been validated based on analysis of several earthquakes (Hayakawa et al. 2010; Pulinets and Ouzounov 2011; Yao et al. 2012; Mahmood et al. 2017, 2018), although the transfer mechanism of seismic/ electromagnetic is not clearly understood (Mahmood 2019).

It is widely accepted that seismological precursor studies generally consider the anomalous change in surface temperature subject to a significant earthquake as a precursory signal. Our study, unlike others mentioned above, discusses the variation in air temperature in a period of no significant earthquake. The motivation of such investigation can briefly be presented as follows. First, in addition to the tectonic stress changes, as has typically been considered in seismology, relatively small changes in stress in subsurface can also result from climate-like forcing (non-tectonic forcing) affecting the micro-seismicity of the area (Buis 2019). The climate-induced stress changes, probably because of their small magnitudes, might or might not be followed by a major earthquake (Buis 2019). Second, there is no single existing method for earthquake precursor monitoring that can provide reliable earthquake forecasting on a regional scale, mainly because of the complexity of earthquake processes and also partly because of the diverse tectonic settings where seismic activities take place (Ouzounov 2018). According to that study, earth observations both space and ground-based present new possibilities by observing possible lithosphere-atmosphere coupling. Third, the build-up of tectonic stress results in the enhanced thermal infrared (TIR) emission from earth's surface (surface temperature rise) by way of degassing from rocks under stress and/or P-hole (sites of electron deficiency) activation in stressed rock volume and their recombination at the rock-air interface (Saraf et al. 2008; Ouzounov 2018). It is worth mentioning that the TIR emission from the rocks under stress is different from frictional heat that develops at the fault surfaces during rupture giving rise to large tectonic events. Thus, the pre-earthquake thermal anomaly is not necessary to precede major earthquakes always (Banerjee 2007). The occurrence of a major tectonic event following the TIR anomaly is constrained by frictional heat, however. Finally, the TIR emission ultimately affects the atmosphere by ionizing air, where ionization is caused by radon discharge and exchange of heat energy causing the release of latent heat (Natarajan and Philipoff 2018). A recent study shows that the proxies of the thermal anomaly (emanation of radon, P-hole, escape of $\mathrm{CO}_{2}, \mathrm{CH}_{4}$, and other greenhouse gases, etc.) may show up anomalous changes at different altitudes from the subsurface to the atmosphere in relation to the 2015 Nepal earthquake (Jing et al. 2019). In the line of the above thoughts, we think that earth observations from both ground and atmosphere could provide some resemblance with earthquake processes.

To this end, we made a very first attempt to understand such a correlation between these parameters with the help of data obtained by conducting short-term multi-parametric geophysical experiments in the Latur-Killari earthquake prone area of western India, where seismogenesis still remains a puzzle in sense to understand what tectonic factors are responsible for earthquake genesis. In turn this piece of study may open an ample avenue for further research in the field of earthquake precursory study. 


\section{Methods/experimental}

\section{Precursor observed}

On 18 June 2007 at 7.20 am during monsoon period, the digital display of an aircraft from Mumbai to Hyderabad flight showed that outside temperature at $11,272 \mathrm{~m}$ was $-17^{\circ} \mathrm{C}$ to $-18^{\circ} \mathrm{C}$ on its usual path near the Sholapur-Gulberga sites (see Fig. 1a for site locations) and up to a location where aircraft started descending for landing at Hyderabad airport. Table 1 shows the details of temperature displayed on the Sholapur-Gulberga-Hyderabad sector. The temperature data listed in Table 1 were derived from the Global Positioning System (GPS) radio occultation observation from aircraft. The occultation data processing system uses signals continuously emitted by the GPS satellites. One of the sensors of a pitotstatic system accurately positioned in the airflow measures the temperature that is obtained from the Air Data Reference System (ADRS) display on board an aircraft. It was a normal Mumbai-Hyderabad flight during monsoon environment, except the abnormal outside temperature at 11272 meters height, with the atmospheric temperature at such height normally in the range of $-38^{\circ} \mathrm{C}$ to $-42^{\circ} \mathrm{C}$ in the Sholapur-Gulberga area, as recorded by the Global Positioning System (GPS) radio occultation technique.

In order to understand whether there exists a correlation between this event and changes in any subsurface geophysical parameters and investigate possible causes of such a conspicuous rise in temperature, we conducted a short-term multi-parametric geophysical experiment in the study area. The experiment includes monitoring seismicity of the area, fluctuations of ground water level, and soil gas helium, which are discussed in detail in the 'Results and Discussion' section.

\section{Results And Discussion}

The results of our investigations based on the monitoring of each of the geophysical parameters are discussed as follows.

\section{Precursory parameters}

\section{(i) Seismicity of the Latur-Killari area}

The main shock of the 1993 Latur earthquake occurred in the Deccan Plateau, a typical stable continental region (Fig. 1a). Geologically the area belongs to the Deccan Trap Plateau basalts of the Paleocene age that are composed of a series of lava-flows in western and central India. Several studies showed that the study region was also impacted by historical earthquakes (Rajendran et al., 1996; Gupta et al. 1999). A maximum intensity of VIII+ (MSK scale) was assigned to the 1993 earthquake. The aftershocks were monitored by a network of up to 21 stations between October 8, 1993 and January 31, 1994. A majority of the aftershocks occurred within a $10 \mathrm{~km}$ radius from the main shock. On the basis of the location of aftershocks in the first few days, a plane dipping at $45^{\circ}$ towards the southwest and striking 
at $135^{\circ}$ is inferred to be the fault plane (Fig. 1b) for this event. The fault plane solution of the main shock reveals a reverse faulting mechanism (Gupta et al. 1998).

The 1993 main shock was preceded by immense swarm activities about a year back in 1992; the swarms were followed by a quiescent period until a major earthquake took place in September 1993. Twenty six events were recorded by the CSIR-NGRI seismological observatory at Hyderabad from 18 October to 15 November 1992 in the Latur-Killari region. The largest magnitude earthquake (M 4.0) was recorded on 18 October, 1992. Since then the area is quiescent except the two earthquakes of magnitude 3.0 and 3.4 in January 2006. Dissimilarity between the swarm activity in 1992 and two earthquakes in January 2006 was not the enough reason to stop further probing, in spite of the fact that a time span of 14 years (from 1993 until 2007) is too short to build up the stress for a major earthquake; however, possibility of smaller to moderate earthquakes cannot be ruled out. Moreover, an earthquake of magnitude 3.8 was observed in the study area on 6 September 2007, although its occurrence in relation to the observed thermal anomaly is not yet clear.

Based on earthquake precursor studies, it is possible that the observed anomaly could result from (i) the thermal sensors that might not have penetrated into thick clouds, as expected in a monsoon time to accurately retrieve the temperature at such height, (ii) changes in meteorological phenomena, and (iii) changes in sub-surface properties, as inferred from geophysical phenomena. Although less likely, but we cannot exclude to mention that if none of the above parametric variations exhibits precursory signature, the temperature sensor of aircraft may malfunction, a case of aviation hazard and a matter of great concern for the safety of passengers. Since the Sholapur-Gulberga region is about $100 \mathrm{~km}$ from the LaturKillari area, where an earthquake of magnitude 6.3 occurred on 29 September, 1993 killing more than 10000 people with heavy damage to property (Rajendran et al. 1996), it was then decided to probe other precursors in the vicinity of the area under operation 'quick please' to get relevant information from several agencies in India or abroad as quickly as possible.

\section{(ii) Fluctuations in ground water level (20 to 23 June, 2007)}

A continuous water-level monitoring was conducted by CSIR-National Geophysical Research Institute (CSIR-NGRI) during the period 20-23 June 2007 around the Latur-Killari area. Fluctuations in water level are worked out by taking care of rain fall recharge and withdrawal of ground water by the pumping. Eleven bore as well as dug wells were selected for continuous monitoring of water level, as shown in Fig. 2. The depth of these bore wells varies from $80 \mathrm{~m}$ to $170 \mathrm{~m}$, whereas the depth of dug wells varies from $10 \mathrm{~m}$ to $30 \mathrm{~m}$. Finding a precursory signal in terms of fluctuation of ground water level during rainy seasons is a very challenging scientific exercise, which was carried out during the monitoring period. Initially, well inventory was carried out for about 50 tube/bore/dug wells in and around the study area as well as along the national highway to Latur. The water levels were monitored continuously with an interval of 1 to 4 hours for four days. The depth of water level in bore wells varies from $11 \mathrm{~m}$ to $38 \mathrm{~m}$ 
below ground level $(\mathrm{bgl})$ and in dug wells it varies from $6 \mathrm{~m}$ to $11 \mathrm{~m} \mathrm{bgl}$. The water levels in most of the wells are in rising order, as shown in Fig. 3(a-c). It has raised up to $3.34 \mathrm{~m}$ in bore well and $5.09 \mathrm{~m}$ in dug well during the period 20-23 June 2007. The rise in water level is mainly due to heavy rainfall in the area.

Fig. 3a shows the change in the water level in bore wells L1 and L5 and dug wells L3 and L9. The wells show an increase in water level except $L 1$, which shows an apparent decline of $0.39 \mathrm{~m}$ over a period of $3 \mathrm{hr} 15 \mathrm{~min}$ at $3.25 \mathrm{pm}$ (on $21^{\text {st }}$ June 2007 from $8.30 \mathrm{AM}$ to $11.45 \mathrm{AM}$ at the rate of $0.12 \mathrm{~m} / \mathrm{hr}$ ) during which there has not been any pumping of water neither from the observation well nor from the vicinity. Had there not been a rise in water level due to rain (at the rate of $0.047 \mathrm{~m} / \mathrm{hr}$ ), the true decline would have been $0.54 \mathrm{~m}$ in this well. This well is situated near Killari, as shown in Fig. 2.

Fig. $\mathbf{3 b}$ shows the variation in water level in bore well L2 and dug well L4. The bore well shows an initial rise in water level, which may be due to rain. However, the decline shown in the hydrograph is due to pumping of water from the well. The dug well shows an initial rise of $5.09 \mathrm{~m}$ followed by a continuous decline. The decline may be due to drainage that flows in the vicinity that did not allow rain water into the well L4.

Fig. $3 c$ shows the variation in water level in four bore wells namely $L 7, L 8, L 9$, and $L 10$. Bore well $L 7$ shows a rise, whereas the other three show apparent decline. Bore well L8 shows a steady decline of 0.03 m over a period of $21 \mathrm{hr} 29 \mathrm{~m}$ (from $21^{\text {st }}$ June $07,11.24$ AM to $22^{\text {nd }}$ June $07,08.55$ AM), while most of the other wells during this period show rise in water level. The other two bore wells $L 10$ and $L 11$ do not show any significant rise or fall in spite of rain. In brief, the bore wells L10 and L8 show fluctuation in water level that might be related to pumping. In principle, such fluctuations in water level can be modeled using stochastic methods to understand the change in sub-surface medium properties. But, it is worth mentioning that monitoring of water level during rain and its withdrawal by pumping is a difficult task to be performed by any signal processing technique, such as the widely used wavelet analysis (Kang and Lin 2007); hence we did not attempt for such detailed study, except for investigating the presence or absence of significant precursory signature that is the main goal of this study.

\section{(iii) Monitoring of Soil Gas Helium $\left(21^{\text {st }}, 24^{\text {th }}\right.$ and $25^{\text {th }}$ June 2007)}

Soil-helium surveys were carried out over the surface rupture zone along the three profiles 1,2 , and 3 , along and either side of the bore well for helium. The profile 2 is shown in Fig. $\mathbf{2}$ and the other two profiles 1 and 3 on either side of the bore well, while not shown in figure for clarity in presentation, are located with $50 \mathrm{~m}$ spacing. Soil-gas data were sampled by drilling a metal probe to a depth of $1 \mathrm{~m}$. The Alcatel Model ASM 100 T helium leak detector was used for soil-gas analysis. Helium concentration was measured to a precision of $0.02 \mathrm{ppm}$ at $5 \mathrm{ppm}$ level.

After the 1993 Latur earthquake, helium surveys were carried out in the vicinity of Latur in an area of $300 \times 200$ sq m, indicating elevated helium levels characterizing the surface ruptures (Rao et al. 1994; Reddy et al. 1994). In order to monitor the long-term changes in the helium field in an area, periodic measurements have been carried out in 1993, 1994, 1995, 1996, 1997, 2005, and 2006. The results of the 
soil-gas helium monitoring, as shown in Table 2, show that there is a rapid decline in the helium signal from $20,000 \mathrm{ppb}$ (after the earthquake occurrence) to $2000 \mathrm{ppb}$ during the period 1993-95 whereas the signal gradually declined thereafter. From the results of helium monitoring during 2005-2007, it is observed that the signal is further declined to around $400 \mathrm{ppb}$.

As a precursory element, these three soil-gas helium profiles 1, 2 and 3 (Fig. 4) were conducted on $21^{\text {st }}, 24^{\text {th }}$ and $25^{\text {th }}$ June, 2007. Table-2 compares the helium values for the years 2005,2006 and June 2007, showing almost the same values during the three-year period. Based on such constant helium value for a relatively long period of three years that can be inferred that the fault in the seismogenic part of the crust is dormant. There is a need to apply advanced tools and methods to operational forecasting techniques based on judicious computational processing that can be applied to remote monitoring of data (Dutta et al., 2012a-b; Dutta et al., 2013).

Summarizing the results of the three geophysical studies described above, we find no noticeable change in the precursors behavior related to the observed thermal anomaly. Accordingly, we suggest that the use of maximum possible numbers of precursor data correlation and interpretation is very useful to avoid the seismic hazards taking place in future.

\section{Factors affecting measurements and signatures of precursor anomaly}

As already mentioned, anomaly in air temperature is expected mostly from stress build-up induced by climate forcing (Buis 2019). Given their effects apply, although of relatively smaller magnitude as compared to tectonic stress build-up, our primary temperature observation at $\sim 11 \mathrm{~km}$ height makes some sense to correlate with other geophysical phenomena even if they are not followed by a significant earthquake. Further tests are needed to confirm the false alarms and hence to better understand the earthquake processes with a deployment of long-term monitoring network of densely spaced stations in the investigated area.

Our observation period is too short to accurately distinguish precursory change. Also, given the environmental effects such as rainfall and pumping, long-term monitoring of air pressure change and trend in aquifer is mandatory for detection of tectonic signal. We also mention here that in addition to the build-up stress as mentioned earlier, fluids can also trigger the micro-seismicity. The presence of fluids in the source area of the 1993 Latur earthquake source area is evidenced from a set of geophysical measurements including gravity, magentotelluric, and seismic wave field measurements (Gupta et al. 1996), as well as the seismic tomographic images showing the low seismic wave speed and high conductivity (Mukhopadhyay et al. 2006). The fluid-dynamic effect on tectonic strain field and the related hydrologic phenomena like diffusivity, pore pressure dissipation, and precursory signals of hydrologic phenomena can be investigated using theory of poro-elasticity (Roeloffs 1996). Considering all these aspects, we can say that our study presents the first results which need further tests with a systematic long-term strategic approach, as a scope of future study. 
Assuming the change in micro-seismicty induced by climate forcing is small, it is hard to know when a fault may be at the critical point subject to climatic processes alone, in agreement with the intermittent (irregular) nature of micro-seismicity on a regional scale (Padhy 2005). Thus, we are thus not in a position to say that climate processes could always trigger a large earthquake. The associated small changes in background micro-seismicity can effectively be detected by a high-resolution dense network of seismic stations with station spacing of the order of a few $\mathrm{km}$ to few tens of kilometers, which is unfortunately lacking now. They are certainly beyond the scope of this study, but could be thought of as long-term strategy for investigating small-scale precursor activities within a multi-disciplinary framework.

The findings of this study pave a way to think well beyond the influence of surface temperatures and conditions in the study of earthquakes that occurs intermittently, in the framework of the widely accepted LAIC. These climatic changes can release energy in sub-surface over time slowly, not necessarily following the mainshock/ aftershock pattern; they do not result in ground shaking like traditional earthquakes do. Several issues still need to be further examined to confirm or falsify the connection of the reported observations with the seismicity. Some of the problems are due to the inevitable limitation of the observational infrastructure at the recent time.

\section{Conclusions}

We investigated the observed rise in atmospheric temperature by more than $20^{\circ} \mathrm{C}$ at 11272 meters altitude above the Sholapur-Gulberga region, which is close to the 1993 Latur-Killari earthquake prone area of western India. Our primary conclusions show that following this thermal anomaly, there are no precursory signals, such as change in (i) seismicity, (ii) ground-water level, and (iii) release of helium gas observed in the study region. The anomaly could rather be attributed to formation and movement of severe local storm under low-level convergence and upper-level divergence, or to lightening oxygen getting converted into ozone as a potential absorber of UV light, or possibly the thermal sensor could not penetrate thick clouds during monsoon time to accurately retrieve the temperature. These findings suggest that conventional geophysical methods alone cannot explain the atmospheric temperature perturbations. A continuous monitoring of temperature over the region could resolve such short-lived temperature variations in upper atmosphere and its relation to the occurrence of major earthquakes. Studies of this kind involving conspicuous thermal anomaly over a limited spatial extent are very useful for better understanding of the atmosphere and terrestrial physics of spatial variation in temperature provided proper precursory validation can be made using advanced forecasting computation tools for analyzing remotely monitored data.

The findings of this study help us to think beyond the influence of surface temperatures and conditions in the study of earthquakes that occurs intermittently in the framework of the widely accepted lithosphere-atmosphere coupling. They may also aid in better understanding false alarm ratios and the overall physics of earthquake preparation. Finally they may provide constraint that earthquake detection based on measurements of these variables could potentially be of use in forecasting. 


\section{Abbreviations}

NCEP: National Centers for Environmental Prediction; GPS: Global Positioning System; CSIR-NGRI: Council of Scientific and Industrial Research - National Geophysical Research Institute.

\section{Declarations}

\section{Acknowledgements}

We sincerely thank the editor Professor Kenji Satake and two anonymous reviewers for their constructive comments. We acknowledge National Remote Sensing Agency (NRSA), Hyderabad; India Meteorological Department, New Delhi and National Atmospheric Research Laboratory (NARL), Tirupathi for sharing and fruitful discussion on data used in this study. Thanks are due to Drs. A. K. Bhatnagar, K. Radhakishnan, A. Saraf, and V. K. Anandan for fruitful discussions and their quick response in clarifying several queries related to this study. We thank Director, CSIR-NGRI for his kind permission to publish this work.

\section{Authors' contributions}

VPD conceived, designed, supervised the experiment, and revised the text. SP analyzed the seismicity data and wrote the paper. NCM, VSS, SRK, and CS conducted field experiments on changes in ground water level and processed the data. GKR and GR conducted the heat flow studies and processed the data. All authors read and approved the final manuscript.

\section{Funding}

This research is supported by the Council of Scientific and Industrial Research - National Geophysical Research Institute (CSIR-NGRI), and partly supported by the Department of Science and Technology, Govt. of India, New Delhi.

\section{Availability of data and materials}

Data supporting the conclusions can be made available on reasonable request to the Director, CSIR-NGRI (director@ngri.res.in) and the corresponding author.

\section{Competing interests}

The authors declare they have no competing interests.

\section{References}

Banerjee $P$ (2007) Analysis of thermal remote sensing data in earthquake studies, M.Tech Dissertation, Department of earth Sciences, Indian Institute of Technology, Roorkee (Unpublished). 

in unravelling geochemical earthquake Precursors. Pure Appl Geophys 122: 157-163.

Baumbach M, Grosser H, Schmidt HG, Paulat A, Rietbrock A, Ramakrishna CVR, Raju PS, Sarkar D, Mohan I (1994) Study of the foreshocks and aftershocks of the intraplate Latur earthquake of September 30, 1993, India. HK Gupta (Ed.). Mem Geol Soc India - Latur Earthquake 35: 33-63.

Buis A (2019). Can climate affect earthquakes, or are the connections shaky? Feature, NASA's Jet propulsion Laboratory

Chen QF, Wang KL (2010) The 2008 Wenchuan earthquake and earthquake prediction in China. Bull Seism Soc Am, 100, 2840-2857.

Cheng WZ, Guan ZJ, Su Q, Ruan X, and Zhang ZW (2011). Precursory before 2008 Wenchuan Ms 8.0 earthquake and their statistical Sinica, 33, 304-318, (Chinese). anomalies in Sichuan region analysis. Acta Seismologica

Choudhury S, Dasgupta S, Saraf AK, Panda S (2006) Remote sensing observations of pre-earthquake. Int J Remote Sens 27: 4381-4396.

Dimri VP (2005a) Fractals in Geophysics and Seismology - An Introduction. VP Dimri (Ed.) Fractal behavior of the earth system, Springer: 1-22

Dimri VP (2005b). Fractal behaviour of the earth system, Springer, pp. 218.

Dutta PK, Naskar MK, Mishra OP (2012a) Test of strain behavior model with radon anomaly in seismogenic area: A Bayesian melding approach, Inter. J. G Geosciences 3 (1), 126-132.

Dutta PK, Mishra OP, Naskar MK (2012b) Decision analysis for earthquake prediction methodologies: Fuzzy interference algorithm for trust validation, Inter. J. Computer Applications 45 (4), 13-20.

Dutta PK, Naskar MK, Mishra OP (2013) Impacts of two-level fuzzy cluster head selection model for wireless sensor network: An energy efficient approaches in remote monitoring scenario, Inter. J. Information Processing 7 (2), 69 - 81.

Guangmeng G (2008) Studying thermal anomaly before earthquake with NCEP data.

The International Archives of the Photogrammetry, Remote Sensing and Spatial Information Sciences. Vol. XXXVII, part B8, Beijing.

Gupta HK, Rao RUM, Srinivasan R, Rao GV, Reddy GK, Dwivedy KK, Banerjee I DC, Mohanty R, Satyasaradhi YR (1999) Anatomy of surface rupture zones of two stable continental region earthquakes, 1967 Koyna and 1993 Latur, India. ～Geophys Res Lett 26: 1985-1988. 
Gupta HK, Sarma SVS, Harinarayana T, Virupakshi G (1996) Fluids below the

hypocentral region of Latur earthquake, India: Geophysical indicators. ～Geophys Res Lett 23: 1569-1572.

Gupta HK, Rastogi BK, Mohan I, Rao CVRK, Sarma SVS, Rao RUM (1998) An investigation into the Latur earthquake of September 29, 1993 in southern India. Tectonophysics 287: 299-318.

Gupta SK, Deshpande RD (2003) Dissolved helium and TDS in ground water from Bhavnagar in Gujarat: Unrelated to seismic events between August 2000 and January 2001. Proc Indian Acad Sci (Earth Planet Sci) 112: 51-60.

Hayakawa M, Fujinawa Y (1994) Electromagnetic phenomena to earthquake prediction, Tokyo. Terra Scientific, pp. 677.

Hayakawa M, Horie T, Muto F, Kasahara Y, Ohta K, Liu LY, Hobara Y (2010) Sub- ionospheric VLF/LF probing of ionospheric perturbations associated with earthquakes: a possibility of earthquake prediction. SICE JCMSI, 3:10-14.

Jing F, Singh RP, Shen X (2019) Land-atmosphere-meteorological coupling associated with the 2015 Gorkha (M 7.8) and Dolakha (M 7.3) Nepal earthquakes, Geomatics, Natural Hazards and Risk 10:1267-1284.

Kang S, Lin H (2007) Wavelet analysis of hydrological and water quality signals in an agricultural watershed. J Hydrology 338:1-14.

King CY (1986) Gas Geochemistry Applied to Earthquake Prediction: An Overview. J Geophys Res 91: 12269-12281.

Ludwin R (2004) Earthquake Prediction. The Pacific northwest seismograph network,

http://www.ess.washington.edu/SEIS/PNSN/INFO_GENERAL/eq_prediction.ht ml.

Mahmood I, Iqbal MF, Shahzad MI, Qaiser S (2017) Investigation of atmospheric anomalies associated with Kashmir and Awaran earthquakes. J Atmos Solar Terr Phys 154: 75-85.

Mahmood I, Iqbal MF, Shahzad MI (2018) Precursor anomalies prior to 2006 Java and 2016 Yujing earthquakes. J Geophys Eng 15:1506.

Mahmood I (2019) Anomalous variations of air temperature prior to earthquakes. Geocarto International.

Mishra OP, Zhao D, Wang Z (2008) The genesis of the 2001 Bhuj India $\quad$ earthquake (Mw 7.6): A puzzle for Penisular India? Indian Minerals, Spcl Issue 61 (62), $149-170$.

Mukhopadhyay S, Mishra OP, Zhao D, Kayal JR (2006) 3-D seismic structure of the source area of the 1993 Latur, India earthquake and its implications for rupture nucleations. Tectonophysics 415: 1- 
16.

Natarajan V, Philipoff P (2018) Observation of surface and atmospheric parameters using "NOAA 18" satellite: a study on earthquakes of Sumatra and Nicobar in $\quad$ regions for the year $2014(M \geq 6.0)$. Nat Hazards 92: 1097-1112.

Noritomi K (1978) Application of precursory geoelectric and geomagnetic phenomena

to earthquake prediction in China. Chinese Geophysics, Washington, AGU 1: $\quad 377-391$.

Outkin VI, Dutta PK, Mishra OP, Naskar MK, Kozlova IA, Yurkov AK (2013a) Radon as early warning tool in tectonic monitoring environment. J Geodetic Sciences 1-6.

Outkin VI, Kozlova IA, Yurkov, AK, Dutta PK, Mishra OP, Naskar MK (2013b) Radon monitoring as a possible indicator of tectonic events: A practical implementation. Earth System Dynamics Discuss 4: 93-107.

Ouzounov D (2018). Earthquake precursors, processes and predictions. Eos 99.

Padhy S (2004). Intermittent criticality on a regional scale in Bhuj. Geophys J Int $\quad 158, \quad 676-680$.

Pulinets S, Ouzounov D (2011) Lithosphere-atmosphere-ionosphere coupling (LAIC) model - An unified concept of earthquake precursors validation. J Asian Earth Sci 41: 371-382.

Rajendran CP, Rajendran K, John B (1996) The 1993 Killari (Latur), central India, earthquake: An example of fault reactivation in the Precambrian crust. Geology 24: 651-654.

Rao GV, Reddy GK, Rao RUM, Gopalan K (1994) Extraordinary helium anomaly over surface rupture of September 1993 Killari earthquake, India. Curr Sci 66: 933-935.

Ravi Prakash M, Dimri VP (2000) Distribution of aftershock sequence of the Latur earthquake in time and space by fractal approach. J Geological Soc India 55:167-174.

Reddy GK, Rao GV, Rao RUM, Gopalan K (1994) Surface rupture of Latur earthquake: The soil-gas helium signature. Geol Soc India Memoir 35: 83-99.

Saraf AK, Choudhury S, Rawat V, Banerjee P, Dasgupta S, Das JD (2008). Detecting earthquake precursor: A thermal remote sensing approach. Geospatial world.

Sengupta D, Mukhopadhyay B, Mishra OP (2018) Seismic cycle and trend prediction of earthquakes in Sumatra-Andaman and Burmese Subduction zones using temporal b-value and Hurst Analysis. J Geol Soc India 92 (6): 661-670.

Subhadra N, Padhy S, Dimri VP (2018) Characterizing spatial heterogeneity based on the b-value and fractal analyses of the 2015 Nepal earthquake sequence. Tectonophysics 722: 154-162. 
Wakita H, Fujii N, Matsuo S, Notsu K, Nagao K, Takaoka N (1978) "Helium Spots": Caused by a diapiric magma from the upper-mantle. Science 200: 430-432.

Yao Y, Chen P, Wu H, Zhang S, Peng W (2012) Analysis of ionospheric anomalies before the $2011 \mathrm{Mw}$ 9.0 Japan earthquake. Chin Sci Bull. 57:500-510.

Yuce G, Ugurluoglu D (2003) Earthquake dates and water level changes in wells in the Eskisehir region, Turkey. Hydrology and Earth System Sciences 7: 777-781.

\section{Tables}

Table 1 Temperature versus height displayed on the airline flight Mumbai-Hyderabad on $18^{\text {th }}$ June 2007. Star $\left(^{*}\right)$ indicates descending height with temperature before landing at airport Hyderabad where surface temperature was $29^{\circ} \mathrm{C}$.

Serial No. Height $(\mathrm{m}) \quad$ Temperature $\left({ }^{\mathrm{o}} \mathrm{c}\right) \quad$ Approx. Location

\begin{tabular}{llll}
\hline 1 & 11272 & -17 & Sholapur \\
2 & 11272 & -17 & Gulberga \\
3 & 9740 & -9 & $*$ \\
4 & 7400 & 5 & $*$ \\
5 & 7200 & 6 & $*$ \\
6 & 5585 & 12 & $*$ \\
7 & 4500 & 17 & $*$ \\
8 & 3500 & 21 & \\
\hline
\end{tabular}

Table 2 Soil-gas helium concentrations. Data are observed over a, profile- 1 , b, profile-2 and 3 in the rupture zone of Latur earthquake near Killari during the period 2005-07 which remain almost same. Location of profile 2 is shown in Fig. 4 and profiles 1 and 3 are on either side of profile 2; $50 \mathrm{~m}$ apart.

\begin{tabular}{lllll}
\hline dd/mm/yyyy & dd/mm/yyyy & dd/mm/yyyy & dd/mm/yyyy & dd/mm/yyyy \\
10/02/2005 & $13 / 10 / 2006$ & $21 / 06 / 2007$ & $24 / 06 / 2007$ & $24 \&$ 25/06/2007 \\
Profile 1 & Profile 1 & Profile 1 & Profile 2 & Profile 3
\end{tabular}

Dist. He Dist. He Dist. He Dist. He Dist. He
(m) (ppb)
(m) (ppb)
(m) (ppb)
(m) (ppb)
(m) (ppb) 


\begin{tabular}{|c|c|c|c|c|c|c|c|c|c|}
\hline 0 & 60 & 0 & 20 & 0 & 150 & 0 & 0 & 0 & 30 \\
\hline \multirow[t]{2}{*}{12} & 60 & 10 & 190 & 10 & 50 & 10 & 30 & 10 & 30 \\
\hline & & 20 & 70 & 20 & 110 & 20 & 170 & 20 & 100 \\
\hline 27 & 90 & 30 & 320 & 30 & 130 & 30 & 100 & 30 & 30 \\
\hline 37 & 90 & 40 & 20 & 40 & 160 & 40 & 100 & 40 & 160 \\
\hline \multirow[t]{2}{*}{52} & 320 & 50 & 270 & 50 & 240 & 50 & 100 & 50 & 200 \\
\hline & & 60 & 210 & 60 & 450 & 60 & 60 & 60 & 160 \\
\hline 67 & 170 & 70 & 470 & 70 & 110 & 70 & 30 & 70 & \\
\hline \multirow[t]{2}{*}{82} & 440 & 80 & 70 & 80 & 30 & 80 & 30 & 80 & 70 \\
\hline & & 90 & 50 & 90 & 300 & 90 & 90 & 90 & 130 \\
\hline 97 & 260 & 100 & 50 & 100 & 280 & 100 & 160 & 100 & 160 \\
\hline \multirow[t]{3}{*}{112} & 150 & 110 & 0 & 110 & 140 & 110 & 90 & 110 & 130 \\
\hline & & 120 & 50 & 120 & 110 & 120 & 150 & 120 & 60 \\
\hline & & 130 & 50 & 130 & 80 & 130 & 120 & 130 & 60 \\
\hline \multirow[t]{2}{*}{142} & 290 & 140 & 80 & 140 & 60 & 140 & 0 & 140 & 100 \\
\hline & & 150 & 50 & 150 & 80 & 150 & 100 & 150 & 100 \\
\hline \multirow[t]{3}{*}{157} & 270 & 160 & 160 & 160 & 110 & 160 & 50 & 160 & 210 \\
\hline & & 170 & 130 & 170 & 0 & 170 & 110 & 170 & 140 \\
\hline & & 180 & 0 & & & 180 & 80 & 175 & 210 \\
\hline 187 & 0 & 190 & 0 & & & 190 & 160 & 180 & 100 \\
\hline 202 & 80 & 200 & 140 & & & 200 & 180 & 185 & 140 \\
\hline \multirow[t]{2}{*}{217} & 0 & 210 & 50 & & & 210 & 150 & 190 & 140 \\
\hline & & 220 & 0 & & & 220 & 80 & 195 & 100 \\
\hline \multirow[t]{2}{*}{232} & 0 & 230 & 0 & & & & & 200 & 110 \\
\hline & & & & & & & & 205 & 110 \\
\hline 247 & 0 & & & & & & & 210 & 100 \\
\hline
\end{tabular}

Figures 

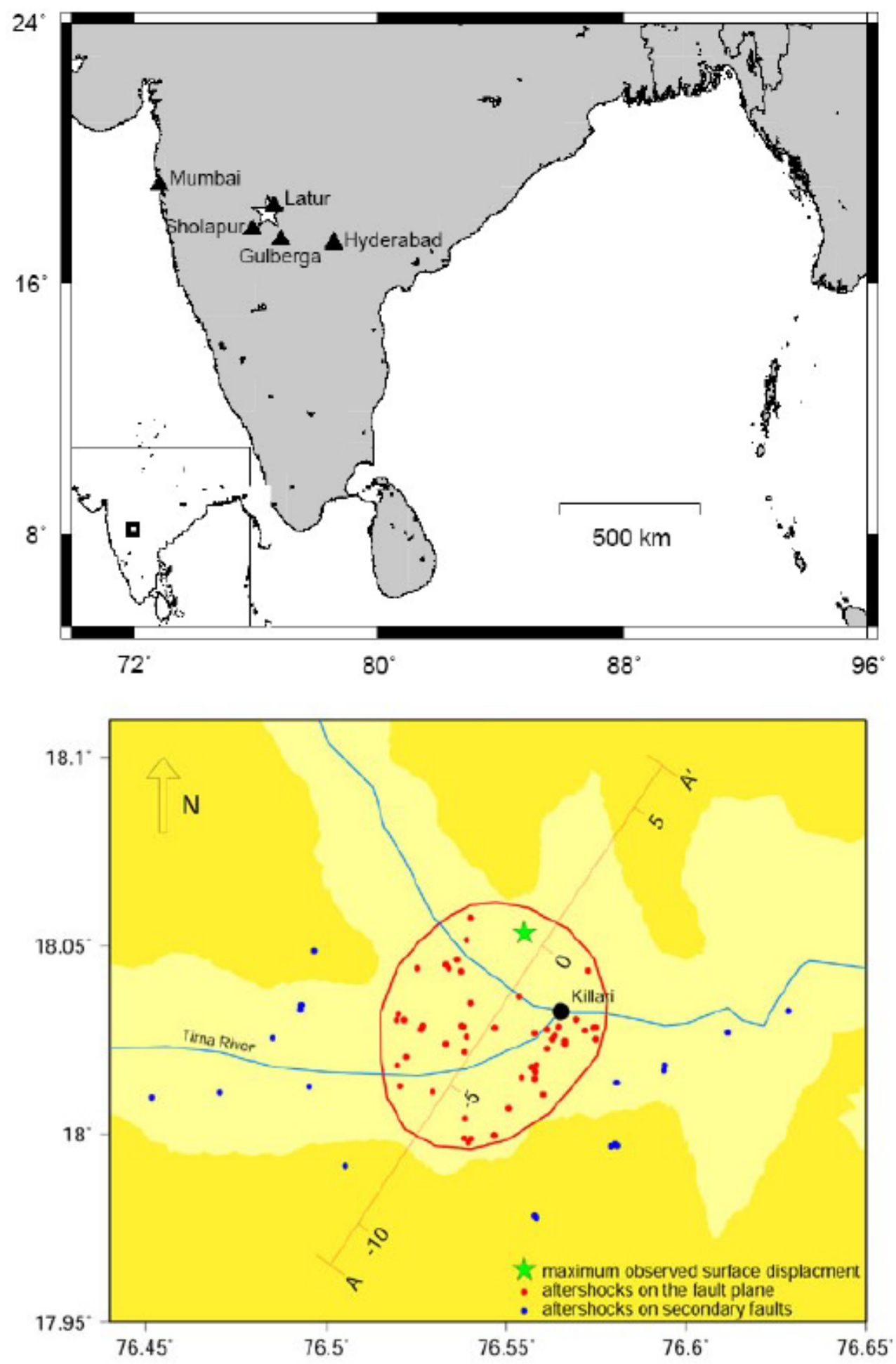

\section{Figure 1}

(a) Map showing the locations of Mumbai, Sholapur, Gulberga, Hyderabad, and Latur areas. Star represents the main shock of 1993 Killari earthquake. Small shaded area in the inset represents the study area. (b) Epicentral map of the recorded aftershocks. The events marked in red are assumed to have occurred on the rupture plane of the 1993 Killari earthquake. The few scattered events marked in blue occurred on secondary faults (after Baumbach et al. 1994). 


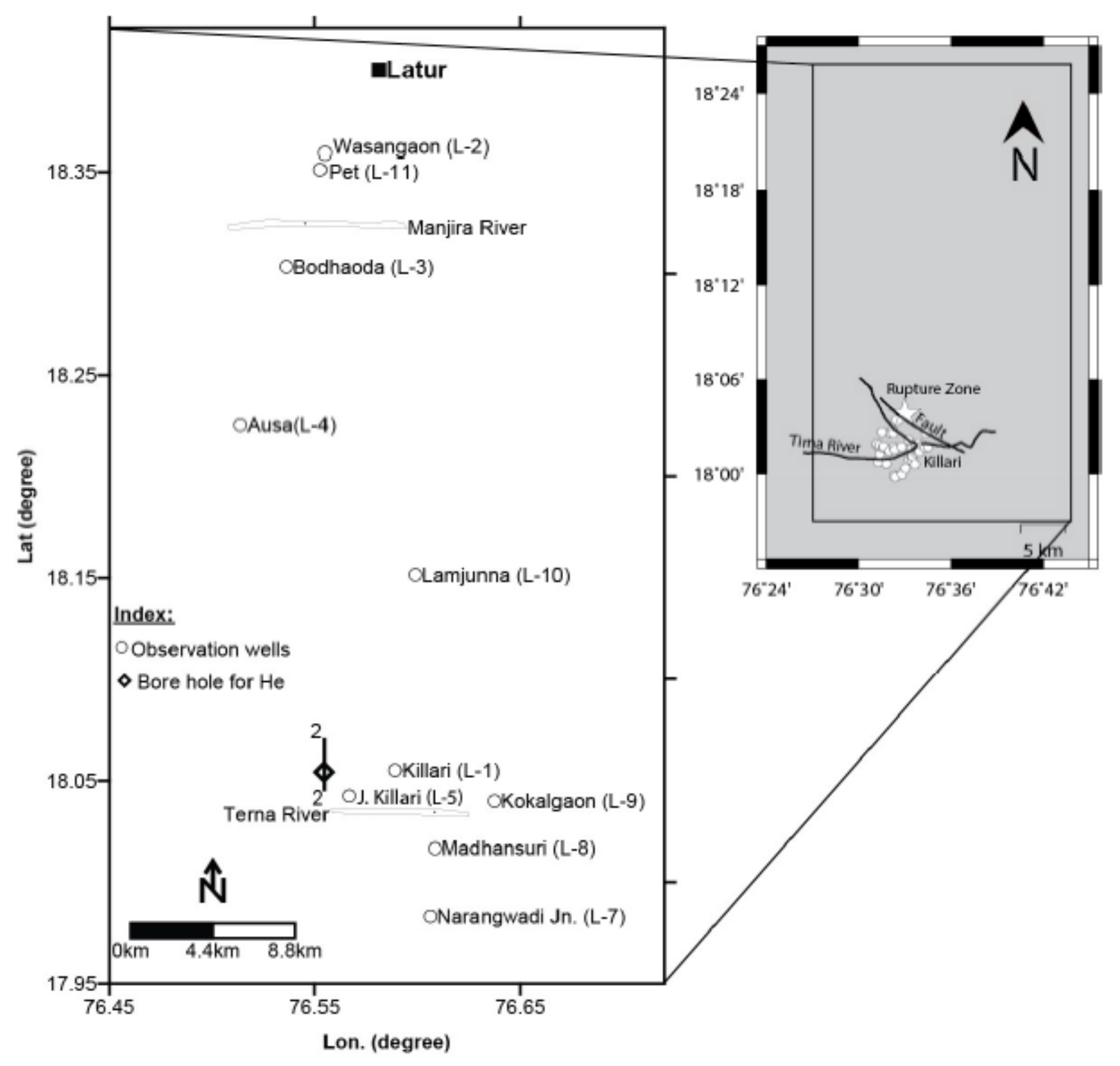

Figure 2

Map showing the location of bore wells $L 1$ to $L 11$ and bore well for helium survey. Three helium profiles 1, 2, 3 are taken along (2-2) and the other two (1-1, 3-3 not shown here for clarity in presentation) on either side of the bore well. Other two profiles are not shown to avoid overlapping of all the three profiles at a profile spacing of $50 \mathrm{~m}$, that is smaller compared to the scale of the figure shown. The location of fault in the source area of the 1993 event is shown with solid line in the inset map, where the mainshock and aftershocks on the fault plane are shown with star and circles, respectively (modified after Baumbach et al. 1994). 
(a)

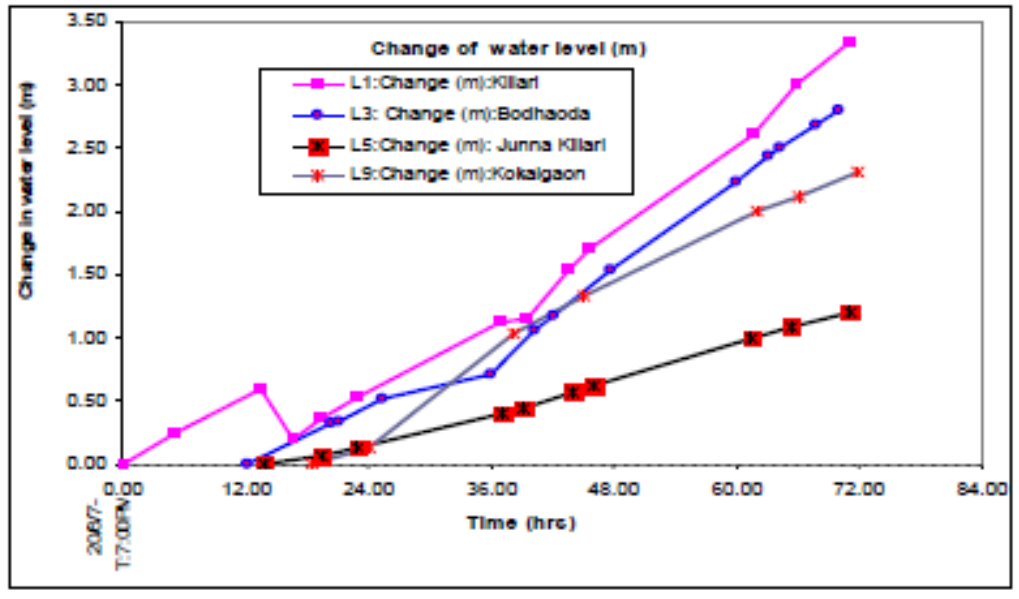

(b)

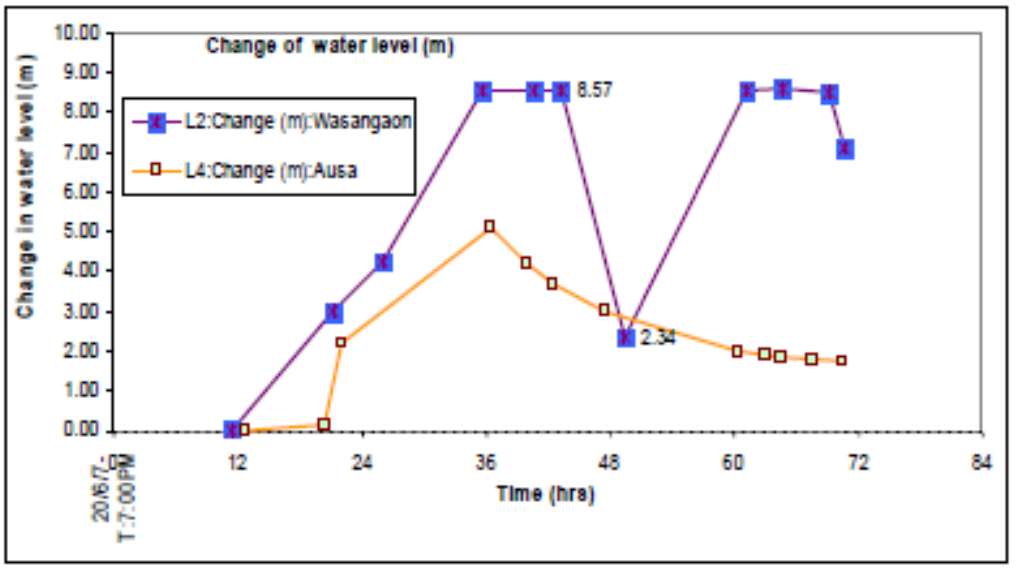

(c)

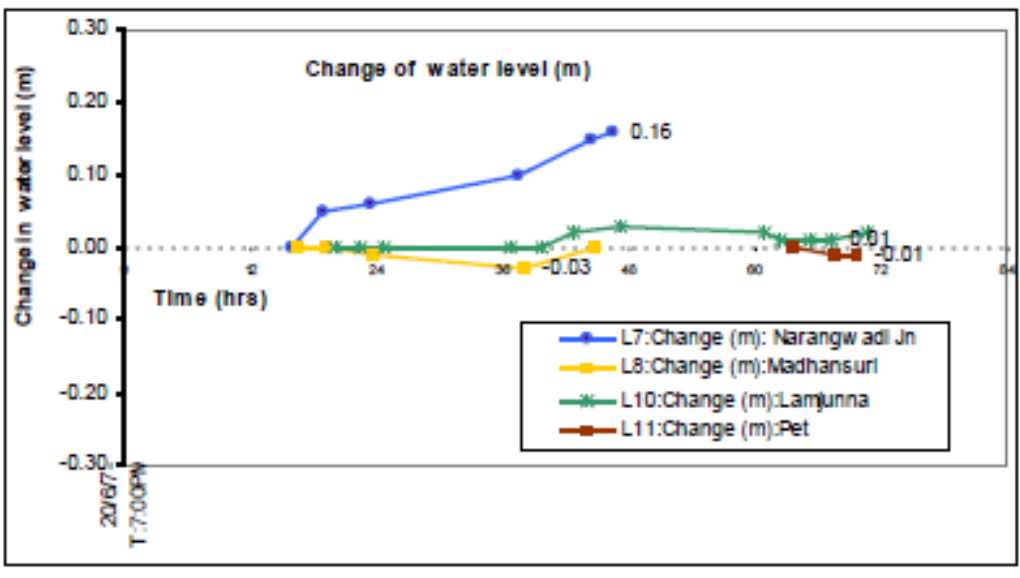

\section{Figure 3}

Fluctuation in water level in bore wells (a) L1, L3, L5, L9, (b) L2, L4, and (c) L7, L8, L10, L11. All the three plots are shown at the same scale; the time scale for Figure $3 c$ is shown at the middle of the figure for convenience in plotting. 
(a)

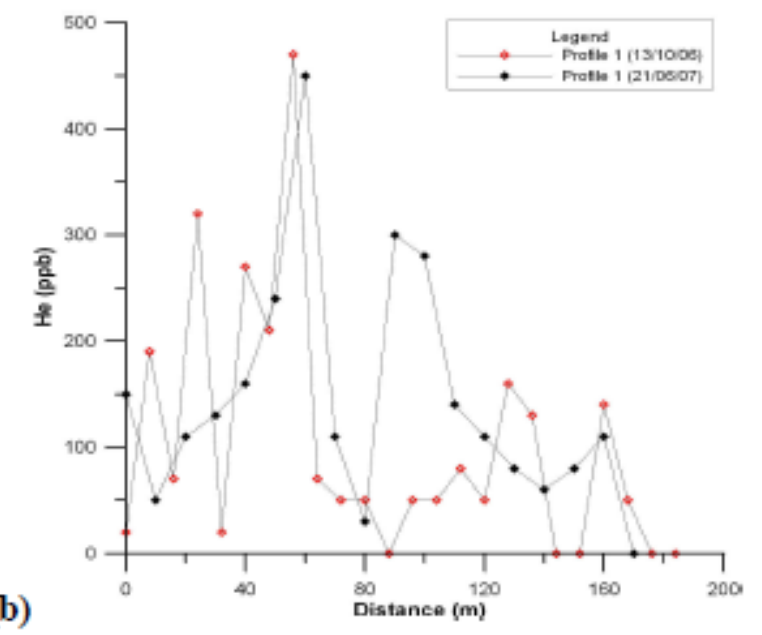

(c)
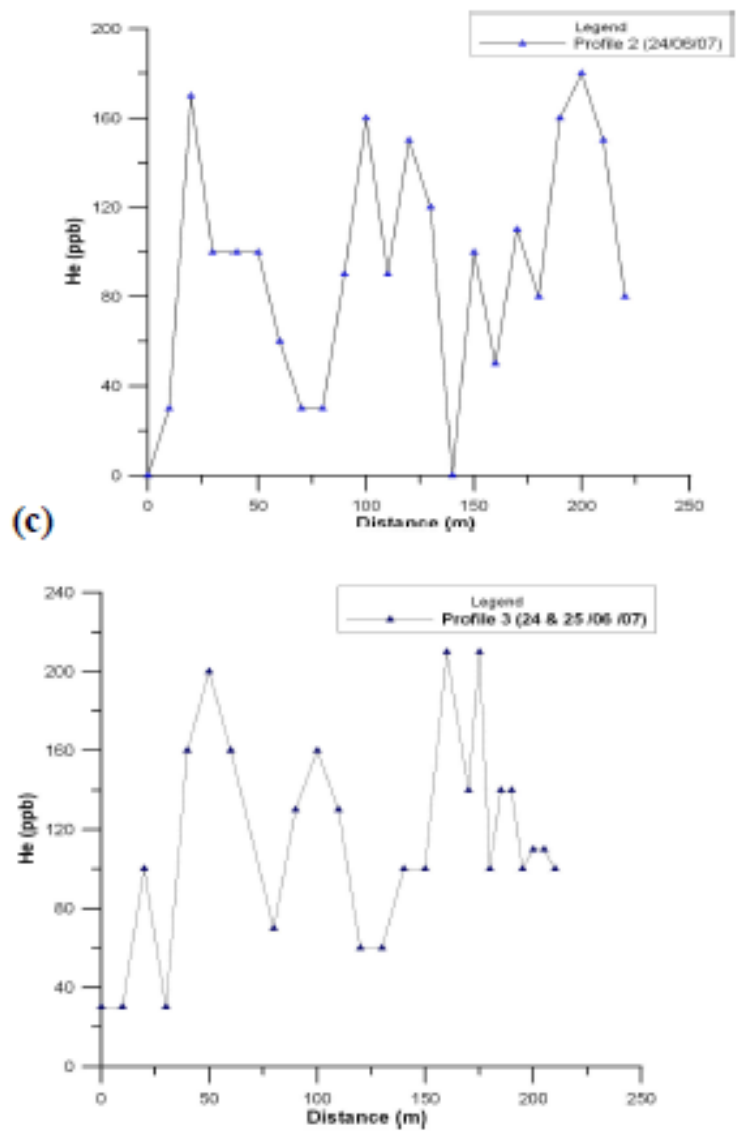

\section{Figure 4}

Soil-gas helium concentrations observed along (a) profile-1, (b) profiles - 2 and 3 in the rupture zone of the 1993 Latur earthquake near Killari during the period 2005-07. Note almost the constant helium value during the whole three-year period. 